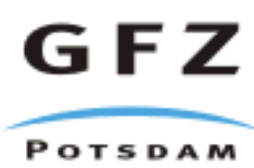

Originally published as:

Taran, M. N., Langer, K., Koch-Müller, M. (2008): Pressure dependence of color of natural uvarovite: the barochromic effect. - Physics and Chemistry of Minerals, 35, 3, 175-177

DOI: 10.1007/s00269-007-0209-z. 


\title{
Pressure dependence of color of natural uvarovite: the
}

\section{barochromic effect}

\author{
M.N. Taran ${ }^{1}$, K. Langer ${ }^{2}$, M. Koch-Müller ${ }^{3}$ \\ ${ }^{1}$ Institute of Geochemistry, Mineralogy and Ore Formation, National Academy of Science of \\ Ukraine, Palladin Ave., 34, 03680 Kyiv-142, Ukraine, E-mail: taran@igmr.relc.com \\ ${ }^{2}$ Applied Geosciences, Technical University of Berlin, D-10623 Berlin, Germany \\ 3 GeoForschungsZentrum, Sektion 4.1, Telegrafenberg, 14473 Potsdam, mkoch@gfz- \\ potsdam.de
}

\begin{abstract}
The electronic absorption spectra of natural uvarovite containing 62 mole $\%$ of the $\mathrm{Cr}^{3+}$ end-member were studied at pressures between $10^{-4}$ and ca. 13 GPa using DAC techniques combined with microscope spectrometric device. With increasing pressure a barochromic effect with change from green to red change of the garnet specimen was observed. This change could be interpreted on the basis of the spectra and the data points derived in an ICE color card. The evaluation of crystal field data from the spectra showed that $10 D q$ of chromium increases on pressure while the Racah parameter $B$, and thus the nature of the chemical bond of $\mathrm{Cr}-\mathrm{O}$ does not change significantly.
\end{abstract}

Key words: high-pressure absorption spectra, chromium, garnet, color

\section{Introduction}

It is well-known that the metal-to-ligand distances of transition metal ion-bearing polyhedra have strong influence on the crystal-field parameter $10 D q$ and Racah parameters $B$ and $C$ of the respective central ion and, as a consequence, on the color of the material under 
consideration (e.g. Burns 1993). With a given crystal structure of the material under consideration changing temperature and pressure and, in case of solid solutions, the molar fraction of the transition metal-bearing component will have effects on the ligand-to-metal distances. Well-known examples are octahedral chromium-bearing oxygen-based minerals and mineral solid solutions, as the corundum-type phases $\left(\mathrm{Al}_{1-\mathrm{x}} \mathrm{Cr}_{\mathrm{x}}\right)_{2} \mathrm{O}_{3}$ (Neuhaus 1960, Pool 1964; for more recent publications refer to Burns 1993). By spectroscopic studies in the temperature range $77-797 \mathrm{~K}$ of a number of $\mathrm{Cr}^{3+}$-containing minerals, it has been shown (Taran et al. 1994) that the chromium-induced color varies with temperature in case of pyrope (see also Eremenko and Polkanov 1972; Ovchinnikov 1975). It could also be shown that this effect is due to an exceptionally strong shift of the spin-allowed $d d$-bands of $\mathrm{Cr}^{3+}$ in the garnet structure.

The effect of pressure to color of $3 d^{\mathrm{N}}$-ion-bearing minerals, especially in cases of coloration due to the ligand-metal charge-transfer or exchange-coupled transition metal ion paring mechanisms, is a known fact (e.g. Mao 1974; Taran et al. 1996; Taran and Rossman 2002). In case of $\mathrm{Cr}^{3+}$-bearing garnets it may be expected that increasing pressure has an opposite effect compared to that of increasing temperature. No study has so far been devoted to this question. It is the aim of the present paper to fill this gap.

\section{Experimental}

The sample studied was the natural dark-green uvarovite from Urals, used before by Taran et al. (1994) in their above study. The sample contains about 62 mole \% of the uvarovite end-member. One grain of the uvarovite sample was ground and polished on both sides to produce a platelet with a thickness of 20 to $30 \mu \mathrm{m}$.

The NUV-VIS high-pressure spectra (up to $\sim 13 \mathrm{GPa}$ ) were recorded with a single-beam microspectrophotometer, which consists of a SpectraPro-275 triple grating monochromator connected to a highly modified MIN-8 polarizing microscope and controlled by a PC. The spectra were scanned with steps $\Delta \lambda=1 \mathrm{~nm}$ in the range $350-450 \mathrm{~nm}\left(c a .28500-22222 \mathrm{~cm}^{-1}\right)$ 
and $\Delta \lambda=2 \mathrm{~nm}$ in the range $420-1000 \mathrm{~nm}\left(\sim 22222-10000 \mathrm{~cm}^{-1}\right)$. To generate hydrostatic pressure up to $\sim 13 \mathrm{GPa}$, the diamond anvil cell (DAC) technique was used as described elsewhere (e.g. Langer 1990, Langer et al. 1997).

\section{Results and discussion}

Figure 1 shows spectra obtained at different pressures. In addition on the right hand side of the Figure, two color photographs are displayed along with the respective spectra. It is obvious that over the total pressure range from $10^{-4} \mathrm{GPa}$ up to ca. $13 \mathrm{GPa}$, a significant change of the color from green to red occurs, whereby at pressures close to $8 \mathrm{GPa}$ a neutral gray color occurred.

The color change is interpreted on the basis of the spectra on the left-hand side and displayed in the CIE color card, show in Figure 2. The shift of the two spin-allowed ddtransitions, ${ }^{4} A_{2 \mathrm{~g}}\left({ }^{4} F\right) \rightarrow{ }^{4} T_{2 \mathrm{~g}}\left({ }^{A} F\right)$ and $\left.{ }^{4} A_{2 \mathrm{~g}}{ }^{A} F\right) \rightarrow{ }^{4} T_{1 \mathrm{~g}}\left({ }^{A} F\right)$, of $\mathrm{Cr}^{3+}$ with pressure is displayed in the upper part of Figure 3. We should recall that the energy of the first transition is equal to the crystal field parameter $10 D q$ of the $3 d^{3}$-configurated $\mathrm{Cr}^{3+}$. By formula $B=\frac{1}{3} \frac{\left(2 v_{1}-v_{2}\right)\left(v_{2}-v_{1}\right)}{\left(9 v_{1}-5 v_{2}\right)}$ (e.g. Burns 1993) and energies of ${ }^{4} A_{2 \mathrm{~g}}\left({ }^{4} F\right) \rightarrow{ }^{4} T_{2 \mathrm{~g}}\left({ }^{4} F\right)$ and ${ }^{4} A_{2 \mathrm{~g}}\left({ }^{4} F\right) \rightarrow{ }^{4} T_{1 \mathrm{~g}}\left({ }^{4} F\right)$ bands, $v_{1}$ and $v_{2}$, derived from the high-pressure spectra, values of Racah parameter $B$ of $\mathrm{Cr}^{3+}$, reflecting the covalency of the oxygen-chromium bond, can be obtained. The data are displayed in the lower part of Figure 3 and indicate that there is no significant change of bonding properties with pressure.

From the material presented it is obvious that

(i) With appropriate distances in a chromium-bearing oxygen-based crystal structure it is possible to observe visually the color changing on pressure, opposite to that related to increasing temperature (see Fig. 1, right part). This is due to the fact that $10 D q$ is proportional to $\bar{R}^{-5}$ with $\bar{R}$ the mean octahedral $\mathrm{Cr}-\mathrm{O}$ distance; 
(ii) The color change observed can be interpreted on the basis of the electronic absorption spectra and are reflected by the respective data points in the ICE color card (Fig. 1, left and Fig. 2). To make the change of the chromaticity coordinates in Fig. 2 more distinct they were calculated for the sample thickness of $0.25 \mathrm{~mm}$;

(iii) The energy of the crystal field parameter $10 D q$ increases, whereas the Racah parameter $B$ does not show a significant dependence on the pressure applied. This latter result implies that the bonding properties of octahedral chromium in the uvarovite crystalline matrix are not strongly influenced by pressure. These observations are different from what was observed on the temperature dependence of crystal field data of chromium in uvarovite (Taran et al. 1994). However, it is confirmed by recent results on synthetic Ni-bearing pyroxenes (Taran et al. 2006), where the Racah parameter $B$ could be determined with higher accuracy than that of $\mathrm{Cr}^{3+}$ in the present case. The reasons for afore mentioned differences in $B$ of chromium and nickel is due much higher width of the band in the former than in the latter system.

All the observations described here, we suggest to be called barochromic effect in correspondence to the well-know terminus thermochromic effect. However, we do not mean that the barochomic effect is just inversely parallel to the thermochromic effect, because this latter effect is more complicate due to that fact it is not only caused by a energy shifts of the respective bands, but also to changes of their intensities with temperature (Taran et al. 1994). 


\section{References}

Burns RG (1993) Mineralogical Applications of Crystal Field Theory. (2nd ed) Cambridge University Press, Cambridge

Eremenko GK, Polkanov YuA (1972) Thermochromic effect in pyrope. Dokl AN SSSR 203:1163-1166 (in Russian)

Langer K (1990) High pressure spectroscopy. In: Mottana A, Burragato F (eds.) Absorption Spectroscopy in Mineralogy, 228-284, Elsevier

Langer K, Taran MN, Platonov AN (1997) Compression moduli of $\mathrm{Cr}^{3+}$-centered octahedra in a variety of oxygen-based rock-forming minerals. Phys Chem Minerals 24: 109-114

Mao HK (1974) Charge-transfer processes at high pressure. In: Strens, RGJ, ed, The Physics of Minerals and Rocks. Wiley, New York. pp.573-581

Neuhaus A (1960) Über die Ionenfarben der Kristalle und Minerale am Beispiel der Chromfarbungen. Z Kristallogr 113: 195-233

Ovchinnikov YuI (1975) On the features of thermochromic effect of pyrope. In: Investigations of Geology and Geophysics of Siberia. Novosibirsk pp 66-68 (in Russian) Pool JrCP (1964) The optical spectra and color of chromium-containing solids. J Phys Chem Solids 25: 1169-1182

Taran MN, Langer K, Platonov AN (1996) Pressure- and temperature-effects on exchangecoupled-pair bands in electronic spectra of some oxygen-based iron-bearing minerals. Phys Chem Mineral 23:230-236

Taran MN, Langer K, Platonov AN, Indutny W (1994) Optical absorption investigation of $\mathrm{Cr}^{3+}$ ion-bearing minerals in the temperature range 77-797K. Phys Chem Minerals 21: 360-372 
Taran MN, Ohashi H, Koch-Müller M (2006) Optical spectroscopic study of synthetic $\mathrm{NaScSi}_{2} \mathrm{O}_{6}-\mathrm{CaNiSi}_{2} \mathrm{O}_{6}$ series pyroxenes. Phys Chem Minerals (Submitted)

Taran MN, Rossman GR (2002) High-temperature, high-pressure optical spectroscopic study of ferric-iron-bearing tourmaline. Am Mineral 87: 1148-1153 


\section{Figure captions}

Figure 1. Electronic absorption spectra of the uvarovite studied at ambient and at high pressures (left part, for the sake of clarity the spectra are shifted along the vertical axis), and color microphotographs of the crystal studied at ambient pressure and at the highest pressure achieved (right part). The smaller pale-rose crystal is a chip of synthetic ruby for pressure calibration. The former photograph taken at ambient pressure displays a bubble to prove a pressure close to $10^{-4} \mathrm{GPa}$. The comparison of the two microphotographs makes the barochromic effect visible.

Figure 2. Projection points of the spectroscopic data in the ICE color card showing the change from the green part to the red part of the color field on increasing pressure. The color coordinates are calculated for a sample thickness of $0.25 \mathrm{~mm}$. D65 is the locus of the CIE 1964 day-light illuminator D65, which corresponds to a correlated color temperature of 6500 K.

Figure 3. Upper part: Energies of the two spin-allowed absorption bands, $v_{1}$ : ${ }^{4} A_{2 \mathrm{~g}}\left({ }^{4} F\right) \rightarrow{ }^{4} T_{2 \mathrm{~g}}\left({ }^{4} F\right)$ and $\mathrm{v}_{2}:{ }^{4} A_{2 \mathrm{~g}}\left({ }^{4} F\right) \rightarrow{ }^{4} T_{1 \mathrm{~g}}\left({ }^{4} F\right)$ of $\mathrm{Cr}^{3+}$, on increasing pressure. The low energy band corresponds to the crystal field parameter $10 D q$. Lower part: Racah parameter $B$ as calculated from the energies of the just mentioned transitions, versus pressure. Solid and open quadrants represent data obtained in the present study, the former are taken on pressure increase, the latter on pressure release. Crosses represent data obtained earlier (Langer et al. 1997). 


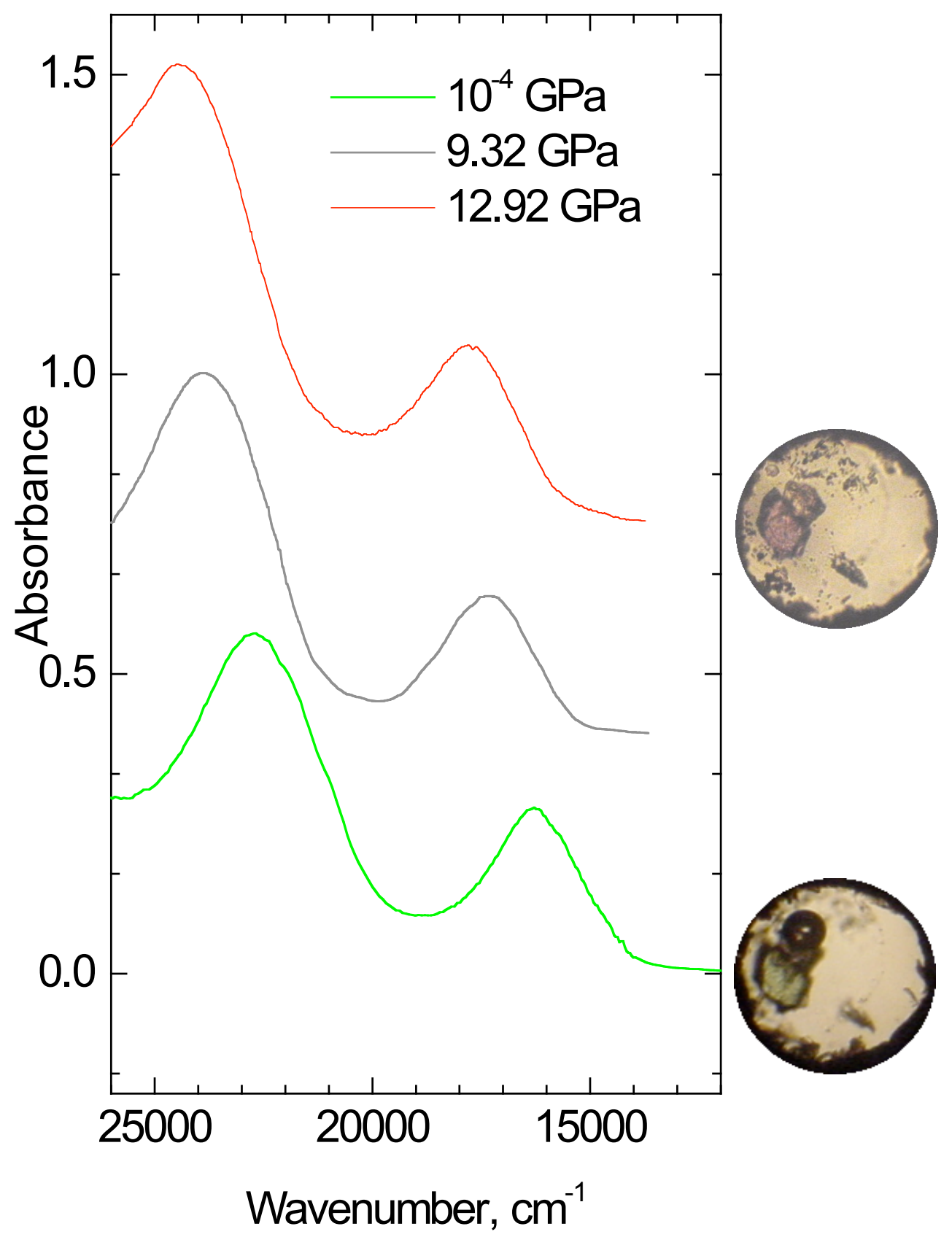

Figure 1. Electronic absorption spectra of the uvarovite studied at ambient and at high pressures (left part, for the sake of clarity the spectra are shifted along the vertical axis), and color microphotographs of the crystal studied at ambient pressure and at the highest pressure achieved (right part). The smaller pale-rose crystal is a chip of synthetic ruby for pressure calibration. The former photograph taken at ambient pressure displays a bubble to prove a pressure close to $10^{-4} \mathrm{GPa}$. The comparison of the two microphotographs makes the barochromic effect visible. 


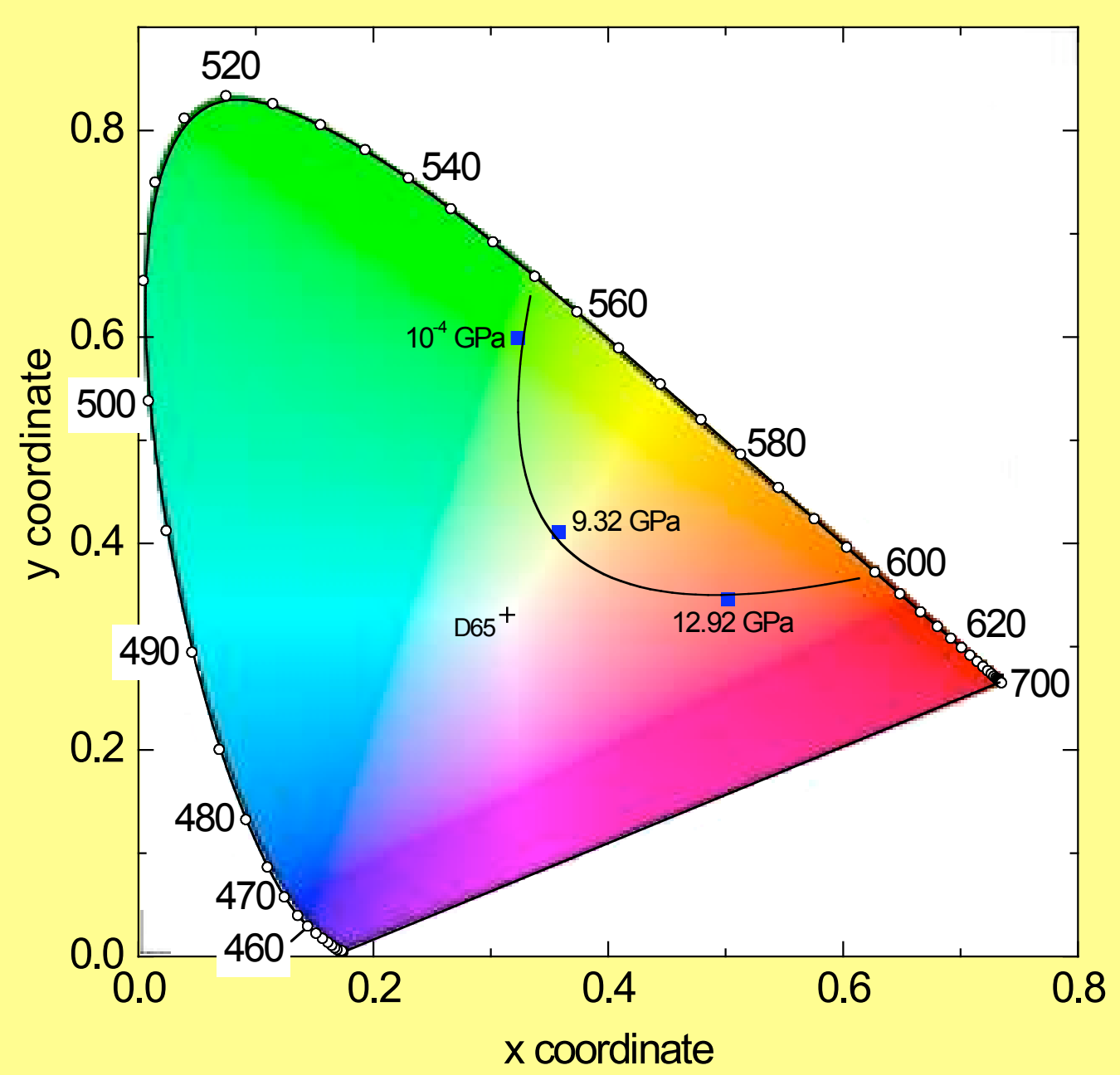

Figure 2. Projection points of the spectroscopic data in the ICE color card showing the change from the green part to the red part of the color field on increasing pressure. The color coordinates are calculated for a sample thickness of $0.25 \mathrm{~mm}$. D65 is the locus of the CIE 1964 day-light illuminator D65, which corresponds to a correlated color temperature of $6500 \mathrm{~K}$. 

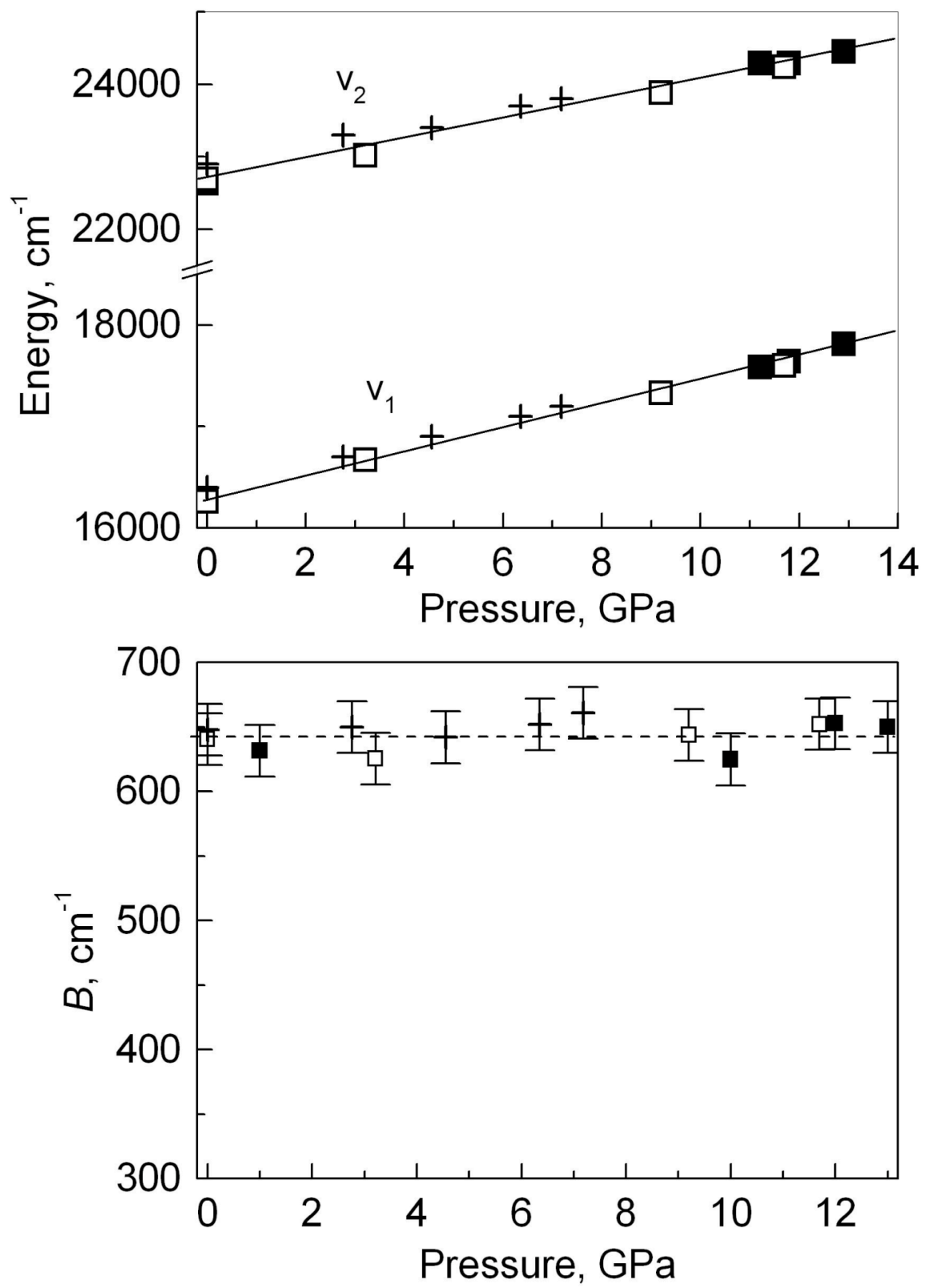

Figure 3. Upper part: Energies of the two spin-allowed absorption bands, $v_{1}:{ }^{4} A_{2 \mathrm{~g}}\left({ }^{4} F\right) \rightarrow{ }^{4} T_{2 \mathrm{~g}}\left({ }^{4} F\right)$ and $\left.v_{2}:{ }^{4} A_{2 \mathrm{~g}}\left({ }^{4} F\right) \rightarrow{ }^{4} T_{1 \mathrm{~g}}{ }^{4} \mathrm{~F}\right)$ of $\mathrm{Cr}^{3+}$, on increasing pressure. The low energy band corresponds to the crystal field parameter $10 D q$. Lower part: Racah parameter $B$ as calculated from the energies of the just mentioned transitions, versus pressure. Solid and open quadrants represent data obtained in the present study, the former are taken on pressure increase, the latter on pressure release. Crosses represent data obtained earlier (Langer et al. 1997). 